\title{
Molecular genetic heterogeneity in autosomal dominant drusen
}

Emma E Tarttelin, Cheryl Y Gregory-Evans, Alan C Bird, Richard G Weleber, Michael L Klein, James Blackburn, Kevin Gregory-Evans

Objective-Autosomal dominant drusen is of particular interest because of its phenotypic similarity to age related macular degeneration. Currently, mutation R345W of EFEMP1 and, in a single pedigree, linkage to chromosome $6 \mathrm{q} 14$ have been causally related to the disease. We proposed to investigate and quantify the roles of EFEMP1 and the 6q14 locus in dominant drusen patients from the UK and USA.

Design-Molecular genetic analysis.

Participants-Ten unrelated families and 17 young drusen patients.

Main outcome measures-Exons 1 and 2 of EFEMP1 were characterised by 5 ' rapid amplification of cDNA ends and direct sequencing. Exons 1-12 of EFEMP1 were then investigated for mutation by direct sequencing. A HpaII restriction digest test was constructed to detect the EFEMP1 R345W mutation. Marker loci spanning Results-Only seven of the 10 families $(70 \%)$ and one of the 17 sporadic patients (6\%) had the R345W mutation. The HpaII restriction digest test was found to be a reliable and quick method for detecting this. No other exonic or splice site mutation was identified. Of the three families without EFEMP1 mutation, two were linked to the 2 p16 region.

Conclusions-EFEMP1 R345W accounts for only a proportion of the dominant drusen phenotype. Importantly, other families linked to chromosome $2 \mathrm{p} 16$ raise the possibility of EFEMP1 promoter sequence mutation or a second dominant drusen gene at this locus. Preliminary haplotype data suggest that the disease gene at the $6 \mathrm{q} 14$ locus is responsible for only a minority of dominant drusen cases. (F Med Genet 2001;38:381-384)

Keywords: autosomal dominant drusen; molecular genetics

Drusen deposits in the macular region of the retina are found in an important set of inherited blinding conditions. These may be subdivided into those conditions where drusen are the earliest and principle finding occurring before 50 years of age and those conditions where drusen are a minor secondary feature, for example, Sorsby's fundus dystrophy. All pedigrees documented to date within the former subgrouping have been reported to exhibit autosomal dominant inheritance and so are said to express a "dominant drusen" phenotype. It is not yet known whether the dominant drusen retinopathy in these different pedigrees represents one or a number of distinct disease entities. ${ }^{1}$ Eponymous types of dominant drusen include Doyne's honeycomb retinal degeneration (DHRD) and malattia leventinese (ML). In DHRD, large drusen deposits have been described at the macula and around the edge of the optic nerve head. ${ }^{2}{ }^{3}$ In $\mathrm{ML}$, as well as macular drusen, small, discrete drusen are also seen radiating into the peripheral retina. These radial deposits are described as continuous with or internal to the basement membrane of the retinal pigment epithelium. ${ }^{4}$ Macular drusen are also a hallmark of age related macular degeneration (ARMD), a complex genetic disorder that accounts for $50 \%$ of blind registration in the developed world. ${ }^{5}$ Characteristically, drusen are seen clinically before the sixth decade of life in dominant drusen pedigrees, but later than this in ARMD.

Both ML and DHRD have been mapped to chromosome $2 \mathrm{p} 16^{67}$ and a single mutation

Table 1 Haplotype data in families linked to the chromosome $2 p 16$ dominant drusen locus. Italicised area indicates common haplotype and thus common ancestry. Bar indicates EFEMP1 intragenic markers

\begin{tabular}{|c|c|c|c|c|c|c|c|c|c|c|}
\hline \multirow[b]{2}{*}{ Pedigree } & \multirow[b]{2}{*}{$D 2 S 2739$} & \multirow[b]{2}{*}{ D2S2352 } & \multirow[b]{2}{*}{$D 2 S 2251$} & \multirow[b]{2}{*}{$133018 \mathrm{CA}$} & \multicolumn{4}{|c|}{$E F E M P 1$} & \multirow[b]{2}{*}{$322 A 4 A A T$} & \multirow[b]{2}{*}{$D 2 S 378$} \\
\hline & & & & & Intron 4 & Intron 8 & Intron 9 & $\begin{array}{l}\text { R345W } \\
\text { mutation }\end{array}$ & & \\
\hline UK1 & 7 & 2 & 11 & 2 & 1 & 2 & $U$ & Yes & 3 & 3 \\
\hline UK2 & 10 & 5 & 11 & 3 & 1 & 2 & $U$ & Yes & 3 & 3 \\
\hline UK3 & 10 & 5 & 11 & 3 & 1 & 2 & $U$ & Yes & 3 & 3 \\
\hline UK4 & 3 & 5 & 11 & 3 & 1 & 2 & $U$ & Yes & 3 & 3 \\
\hline US1 & 5 & 4 & 11 & 3 & $U$ & 2 & 2 & Yes & 3 & 3 \\
\hline US2 & 10 & 2 & 8 & 3 & 1 & 2 & 2 & Yes & 2 & 2 \\
\hline US3 & 6 & 2 & 10 & 3 & 1 & 2 & 2 & Yes & 3 & 2 \\
\hline UK5 & 7 & 2 & 8 & 3 & $\mathrm{U}$ & 2 & 2 & No & 3 & 9 \\
\hline UK6 & 6 & 7 & 6 & 1 & $\mathrm{U}$ & 2 & 2 & No & 2 & 8 \\
\hline
\end{tabular}

$\mathrm{U}=$ uninformative. Families UK5 and UK6, despite linkage to the region, do not share the common haplotype or have the $R 345 \mathrm{~W}$ mutation. 


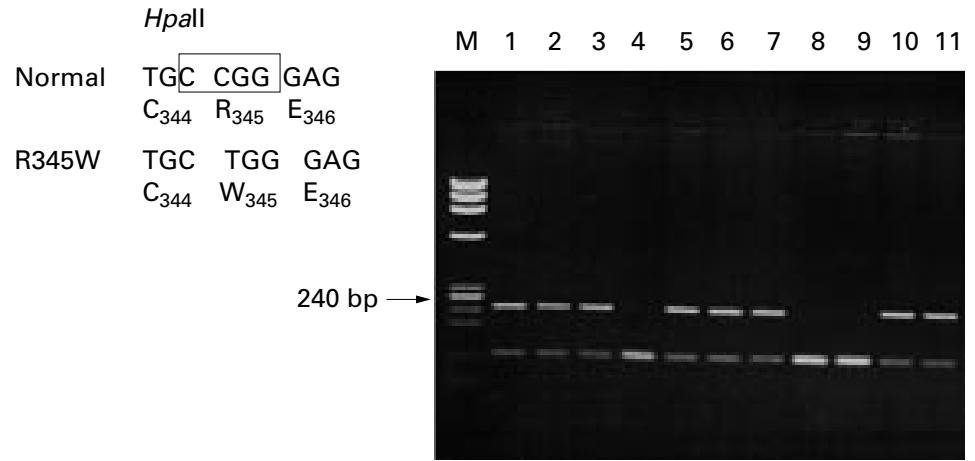

Figure 1 Restriction enzyme digestion assay for the arginine to tryptophan mutation at codon 345 of the EFEMP1 gene. Eleven members of pedigree US1 are presented. The mutation abolishes a HpaII site. PCR was used to amplify a 240 bp fragment spanning exon 10 from patient DNA. The PCR products were digested with the restriction enzyme HpaII and run out on agarose gels. Patients 4, 8, and 9 are unaffected and therefore do not have the mutation. Patients 1-3, 5-7, and 10-11 are all affected and have the Arg345Trp mutation. $M$ represents the DNA marker PhiX174/HaeIII.

(R345W) has been identified in the EFEMP1 gene. ${ }^{8}$ This was found in pedigrees with both ML and DHRD and it has been suggested that this mutation originates from a common ancestor and that perhaps most cases of dominant drusen derive from this. More recently, a single dominant drusen pedigree has been mapped to chromosome $6 \mathrm{q} 14 .^{9}{ }^{10}$ In this study, we proposed to determine whether these molecular genetic localisations are relevant to a large cohort of dominant drusen pedigrees identified in the UK and USA.

\section{Methods}

FAMILY AND CLINICAL DATA

Ten unrelated families expressing a dominant drusen phenotype and 17 young cases without a family history (16 British and one American patient) were enrolled into the study. Informed consent for clinical and genetic assessment was obtained in accordance with the Declaration of Helsinki. The cohort comprised seven families from the UK (UK1 to UK7) and three families from the USA (US1 to US3) (table 1). Families UK1 and US2 have previously been

\begin{tabular}{|lrl|}
\hline \multicolumn{3}{|l|}{ Chromosome 2 } \\
D2S2352 & 2 & 5 \\
D2S2251 & 9 & 8 \\
322A4AAAT & 1 & 2 \\
D2S378 & 5 & 4 \\
\multicolumn{2}{l|}{ Chromosome 6} \\
cen & & \\
D6S460 & 3 & 1 \\
D6S1644 & 5 & 2 \\
D6S462 & 2 & 3 \\
ter & \multicolumn{1}{|l|}{} \\
\hline
\end{tabular}

\begin{tabular}{|lll|}
\hline \multicolumn{3}{|l|}{ Chromosome 2 } \\
D2S2352 & 2 & 4 \\
D2S2251 & 9 & 9 \\
322A4AAAT & 1 & 1 \\
D2S378 & 5 & 8 \\
Chromosome & 6 \\
cen & \\
D6S460 & 3 & 1 \\
D6S1644 & 5 & 1 \\
D6S462 & 2 & 2 \\
ter & & \\
& &
\end{tabular}

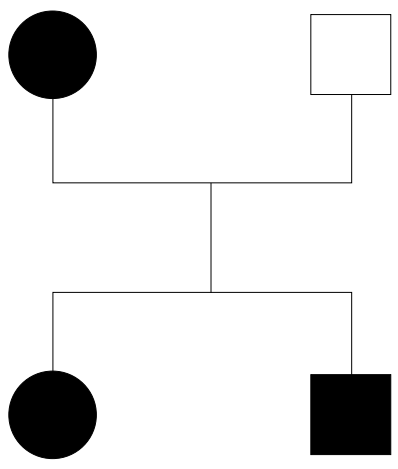

Figure 2 Haplotype data in family UK7 at chromosomes $2 p 16$ and $6 q 14$ linked to the dominant drusen phenotype. Chromosome 2 data show a recombination event suggesting exclusion from linkage. Shaded areas show the common haplotype for the chromosome $6 q 14$ dominant drusen locus in affected children inherited from the affected parent. clinically described. ${ }^{11}{ }^{12}$ UK1 is descended from the patients originally described by $\mathrm{R} \mathrm{W}$ Doyne. $^{2}$ All subjects classified as affected exhibited soft drusen at the macula before 45 years of age. Unaffected status was assigned to those patients with a normal ophthalmic examination and over 55 years of age. Since no other type of inheritance has been described, simplex cases under 45 years of age, with retinal drusen for no other apparent cause, were classified as examples of dominant drusen.

\section{CHARACTERISATION OF 5' END OF EFEMP1 AND} MUTATION SCREEN

The structure of the $5^{\prime}$ end of the EFEMP1 gene including 5 ' untranslated exons 1 and 2 has not been fully established. In order to be able to screen the entire EFEMP1 gene for mutations, we therefore characterised the 5' end of the gene. Two PAC clones containing the EFEMP1 gene were isolated from the RPCI1 PAC library (de Jong), obtained from the HGMP Resource Centre, Hinxton, Cambridge. A $5 \mathrm{~kb} E c o$ RI subclone containing exon 3 of the gene was identified. A combination of 5 ' rapid amplification of cDNA ends (RACE) and genomic sequencing was used to characterise the region upstream of exon 3 including exon 1 (GenBank accession number AY027910) and exon 2 (GenBank accession number AY027911). Using this new information, intronic primers were designed to amplify exons 1 and 2 for mutation screening. These were 1F: AACGCTGGGCTCAGCGCTC and 1R: CATCCCAACAGATGTCACC with an annealing temperature of $60^{\circ} \mathrm{C}$ and 2F: ACTGGAAGATTGCTCTCC and 2R: TCCATTTCAAAGGGGACGG at $55^{\circ} \mathrm{C}$.

Genomic DNA was extracted from peripheral blood lymphocytes from family members using the Nucleon II kit (Nucleon Biosciences). Exons 1 to 12 were then amplified by PCR using primers as listed above for exons 1-2 and using previously described primers for exons 3-12 under standard conditions. ${ }^{8}$ Both strands of each amplified fragment were examined for mutation by direct sequencing using standard protocols. ${ }^{13}$

Since the R345W mutation removes a $\mathrm{HpaII}$ restriction site in exon 10, we investigated whether this could be used as an initial diagnostic test for this mutation. PCR was used to amplify a $240 \mathrm{bp}$ fragment spanning exon 10 from patient DNA. The PCR products were then digested with the restriction enzyme HpaII and run out on agarose gels.

HAPLOTYPE ANALYSIS

Five microsatellite marker loci, D2S2739, D2S2352, D2S2251, D2S2153, and D2S378, spanning approximately $4 \mathrm{cM}$ (Marshmed map $)^{14}$ of the chromosome 2 p16 region linked to dominant drusen, were used to generate haplotype data. Six further marker loci were also used in the chromosome $2 \mathrm{p} 16$ analysis, 133018CA, 322A4AAAT, and four intragenic polymorphisms derived from introns $4,8,9$, and 11 of the EFEMP1 gene. ${ }^{8}$ Six microsatel- 

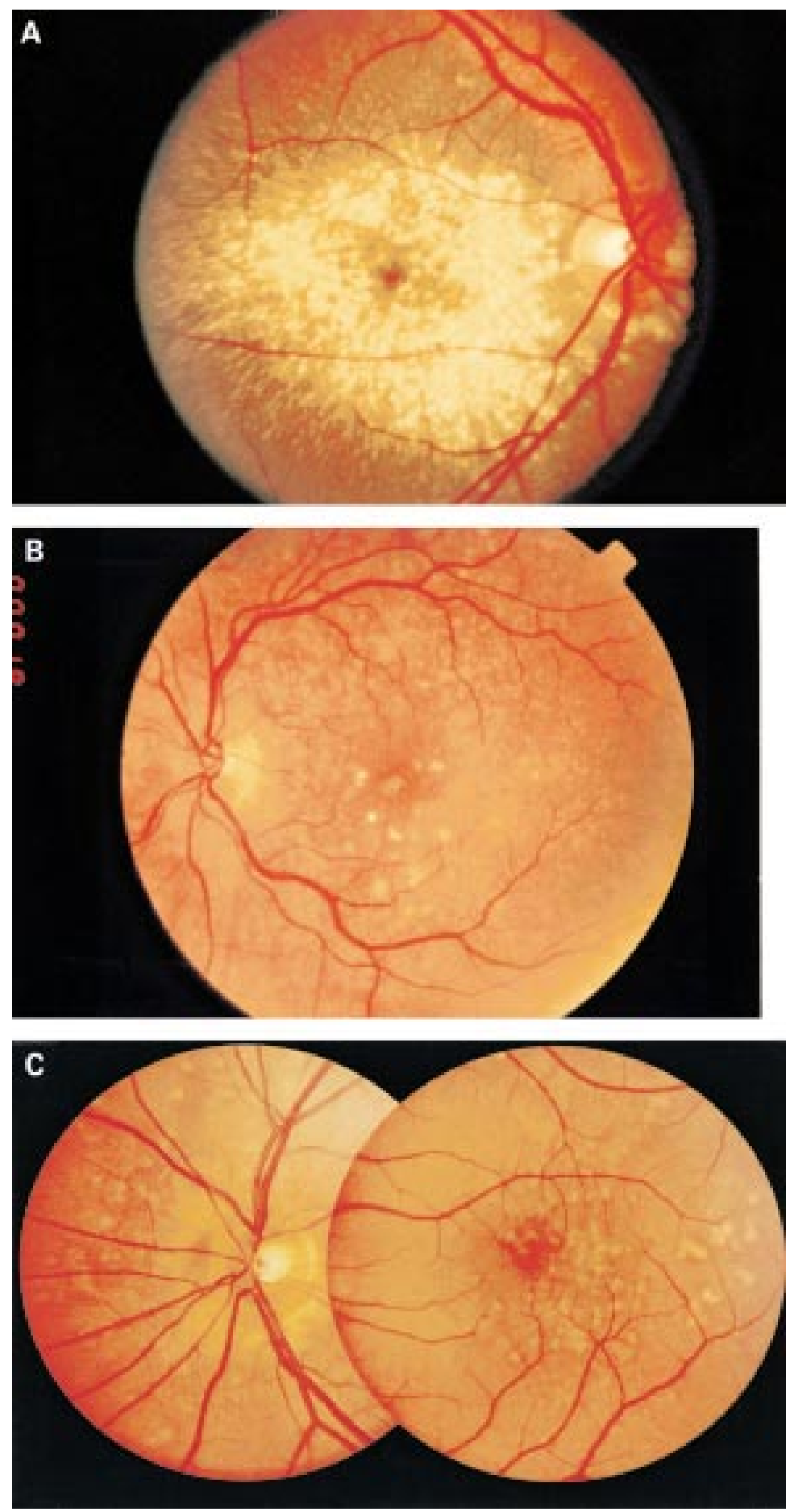

Figure 3 Fundus photographs of patients affected by dominant drusen. (A) A 44 year old patient from pedigree US1 with R345W EFEMP1 mutation. (B) A 63 year old patient (drusen noted from 45 years of age) from pedigree UK6, linked to chromosome $2 p 16$ but without EFEMP1 mutation. (C) A 39 year old sporadic drusen patient who does not have EFEMP1 mutation.

\section{Results}

Mutation screening established that seven of the 10 families $(70 \%$, four British, three American) and one of the 17 simplex cases (6\%, one British patient) had the EFEMP1 R345W mutation. This was further established using the HpaII restriction enzyme digestion assay (fig 1). Haplotype data generated at marker loci spanning the $4 \mathrm{cM}$ linked interval of chromosome $2 \mathrm{p} 16$ showed that these patients all shared a common genetic haplotype across the $1 \mathrm{cM}$ region D2S2251 to D2S378, including intragenic EFEMP1 polymorphisms (table 1). This suggests a founder mutation. It was of particular note that the intragenic marker loci were often uninformative, for example, marker locus intron 11 was uninformative in all families studied.

Three of the 10 families and 16 of the simplex cases were found to be negative for the R345W mutation by HpaII restriction enzyme analysis and direct sequencing of exon 10 (fig 1). Subsequent sequencing of exons 1-9, 11, and 12 in these cases did not identify any other mutation in any exons or at splice site junctions of the EFEMP1 gene. It was noteworthy that each of the three families without the R345W mutation also had different haplotypes at the 2 p16 linked locus, both from each other and from the R345W founder population. This suggests that these families are unrelated to the original common ancestor who had the EFEMP1 mutation (table 1). Interestingly, two of these families, UK5 and UK6, have previously been linked to the 2 p16 disease associated locus. ${ }^{15}$ The other family, UK7, was too small for statistically significant linkage analysis. However, recombination events observed in family UK7 show convincing exclusion of the 2p16 locus (fig 2). Haplotype data for the chromosome $6 \mathrm{q} 14$ dominant drusen locus generated in family $\mathrm{UK} 7$ is presented in fig 2. Recombination events in families UK5 and UK6 excluded linkage to this locus (data not shown).

Clinical photographs of the retina of dominant drusen patients who do not have EFEMP1 R345W mutation are presented in fig 3. Typically, soft macular drusen were noted in each case. It was noteworthy that clinically, in each case, these deposits were confined to the macular region and were neither juxtapapillary (abutting the optic nerve head) nor extended in to the periphery as has been described in many dominant drusen pedigrees with the R345W mutation. ${ }^{3411}$

\section{Discussion}

It is clear from the work presented here that EFEMP1 mutation including R345W accounts for a large but not an overwhelming proportion of cases of dominant drusen. Only $70 \%$ of families and more strikingly only $6 \%$ of sporadic cases showed EFEMP1 mutation. Therefore, although an EFEMP1 mutation screen should be the initial test in the molecular diagnosis of a case of retinal drusen in a patient under 50 years of age, a negative result does not exclude this clinical diagnosis. Abolition of the HpaII restriction site in exon 10, as 
described here for the first time, can be used to enhance the efficiency of EFEMP1 screening for the common R345W mutation (fig 1). In addition, information on untranslated exons 1 and 2 now allows for a more complete assessment of the role of this gene in subjects expressing a drusen phenotype.

It is of particular interest that two pedigrees UK5 and UK6, although showing linkage to chromosome 2p16, did not have an EFEMP1 mutation. This may be interpreted as evidence to suggest a second dominant drusen gene at this locus. Alternatively, these pedigrees may express mutations of the EFEMP1 promoter sequence. No such promoter sequence mutation has yet been associated with outer retinal dystrophy, although $R B 1$ promoter sequence mutation has been associated with retinoblastoma. ${ }^{16}$

Another striking feature of this study was the phenotype seen in dominant drusen cases that did not have EFEMP1 mutation. All had soft macular drusen, but none seemed to exhibit juxtapapillary or hard radial drusen (fig 3B, C). This latter feature is a cardinal sign in $\mathrm{ML} .{ }^{4} \mathrm{In}$ DHRD, juxtapapillary drusen are seen unless there is juxtapapillary atrophy and radial drusen are seen in some cases but not others. ${ }^{11}$ It is of interest that these ML and DHRD pedigrees have all had R345W EFEMP1 mutation. $^{8}$ It is possible that the juxtapapillary drusen and radial drusen are features specific to R345W EFEMP1 although the pedigree recently mapped to $6 \mathrm{q}$ also had members with radial drusen. ${ }^{10}$ This needs to be investigated in further studies.

Family UK7 also did not exhibit EFEMP1 mutation and, significantly, haplotype analysis excluded the chromosome $2 \mathrm{p} 16$ locus. Chromosome $6 \mathrm{q}$ haplotype data, however, may suggest that the dominant drusen phenotype in UK7 is the result of mutation at this locus. The evidence for this is, however, not conclusive and other loci may be relevant. Drusen are a minor feature of a number of other mapped retinal dystrophies including Sorsby's fundus dystrophy (chromosome 22q31), ${ }^{17}$ North Carolina macular dystrophy (chromosome $6 \mathrm{q} 16),{ }^{18}$ and autosomal dominant age related macular degeneration (1q). ${ }^{19}$ Each of these loci should be included in any secondary genome search for the disease gene leading to a retinal drusen phenotype.

We gratefully acknowledge The Wellcome Trust (054517), the Foundation Fighting Blindness, and the British Retinitis Pigmentosa Society (GR524) for their financial support of this work.
1 Piguet B, Haimovici R, Bird AC. Dominantly inherited drusen represent more than one disorder: a historical drusen represent more

2 Doyne RW. A note on family choroiditis. Trans Ophthalmol Soc UK 1910;30:93-5.

3 Pearce WG. Doyne's honeycomb retinal degeneration: clinical and genetic features. Br F Ophthalmol 1968;52:73-8.

4 Dusek J, Streicher T, Schmidt T. Hereditare drusen der bruchschen membran II. Untersuchung von semidunnschnitten und electromikroskopischen ergebnissen. dunnschnitten und electromikroskopischen

5 Evans J, Wormald R. Is the incidence of registrable age-related macular degeneration increasing? Br F Ophthalmol 1996;80:9-14.

6 Heon E, Piguet B, Munier F, Sneed SR, Morgan CM, Forni S, Pescia G, Schorderet D, Taylor CM, Streb LM, Wiles CD, Nishimura DY, Sheffield VC, Stone EM. Linkage of autosomal dominant radial drusen (malattia leventinese) to chromosome 2p16-21. Arch Ophthalmol 1996;114:193-8.

7 Gregory CY, Evans K, Wijesuriya SD, Kermani S, Jay MR, Plant C, Cox N, Bird AC, Bhattacharya SS. The gene responsible for autosomal dominant Doyne's honeycomb retinal dystrophy (DHRD) maps to chromosome $2 \mathrm{p} 16$. Hum Mol Genet 1996;5:1055-9.

8 Stone EM, Lotery AJ, Munier FL, Heon E, Piguet B, Guymer RH, Vandenburgh K, Cousin P, Nishimura D, Swiderski RE, Silvestri G, Mackey DA, Hageman GS, Bird AC, Sheffield VC, Schorderet DF. A single EFEMP1 mutation associated with both Malattia Leventinese and mutation associated with both Malattia Leventinese and 199-202.

9 Kniazeva M, Traboulsi EI, Yu Z, Stefko ST, Gorin MB, Shugart YY, O'Connell JR, Blaschak CJ, Cutting G, Han $\mathrm{M}$, Zhang K. A new locus for dominant drusen and macular degeneration maps to chromosome 6q14. Am f Ophthalmol 2000;130:197-202.

10 Stefko ST, Zhang K, Gorin MB, Traboulsi, EI. Clinical spectrum of chromosome 6-linked autosomal dominant drusen and macular degeneration $A m$ f Ophthalmol 2000;130:203-8.

11 Evans K, Gregory CY, Wijesuriya SD, Kermani S, Jay MR, Plant C, Bird AC. Assessment of the phenotypic range seen in Doyne honeycomb retinal dystrophy. Arch Ophthalmol 1997;115:904-10

12 Edwards, AO, Klein ML, Berselli CB, Hejtmancik JF, Rust K, Wirtz MK, Weleber RG, Acott TS. Malattia leventinese: refinement of the genetic locus and phenotypic variability in autosomal dominant macular drusen. Am $\mathcal{F}$ Ophthalmol 1998;126:417-24

13 Tarttelin EE, Kirschner, LS, Bellingham J, Baffi J, Taymans SE, Gregory-Evans K, Csaky K, Stratakis CA, GregoryEvans CY. Cloning and characterisation of a novel orphan G-protein-coupled receptor localised to human chromosome 2p16. Biochem Biophys Res Commun 1999;260:17480 .

14 Genetic map. http://www.marshmed.org/genetics/

15 Kermani S, Gregory-Evans K, Tarttelin EE, Bellingham J, Fox M, Plant C, Bhattacharya SS, Gregory-Evans CY. Refined genetic and physical positioning of the gene for Doyne honeycomb retinal dystrophy (DHRD). Hum Genet 1999;104:77-82.

16 Cowell JK, Bia B, Akoulitchev A. A novel mutation in the promoter region in a family with a mild form of promoter region in a family with a mild form of retinoblastoma indicates the location of a new reg
domain for the RB1 gene. Oncogene 1996;12:431-6.

17 Wijesuriya SD, Evans K, Jay MR, Davidson C, Weber BHF, Bird AC, Bhattacharya SS, Gregory CY. Sorsby's fundus dystrophy in the British Isles: demonstration of a striking founder effect by microsatellite-generated haplotypes. Genet Res 1996;6:92-101.

18 KW Small, S Yelchits, N Udar, Klein R, Garcia C, Gallardo G, Puech B, Puech V, Saperstein D, Lim J, Haller J, Flaxel C, Kelsell R, Hunt D, Evans K, Lennon F, Pericak-Vance M. North Carolina macular dystrophy (MCDR1) locus: a fine resolution genetic map and haplotype analysis. Mol Vision 1999;5:38. http://www.molvis.org/molvis/v5/p38/

Vision 1999;5:38. http://www.molvis.org/molvis/v5/p38/
1 Klein ML, Schultz DW, Edwards, A, Matise TC, Rust K, Berselli CB, Trzupek K, Weleber RG, Ott J, Wirtz MK, Acott TS. Age-related macular degeneration. Clinical features in a large family and linkage to chromosome 1q. Arch Ophthalmol 1998;116:1082-8. 